\title{
Analytical investigations of the accuracy of the small diameter tool-joint tapered thread made by a lathe machining
}

\author{
Oleh Onysko, Volodymyr Kopei, lulia Medvid, \\ Vitalii Panchuk, Lolita Pituley, Viktor Vryukalo \\ Ivano-Frankivsk National Technical University \\ of Oil and Gas, Ukraine
}

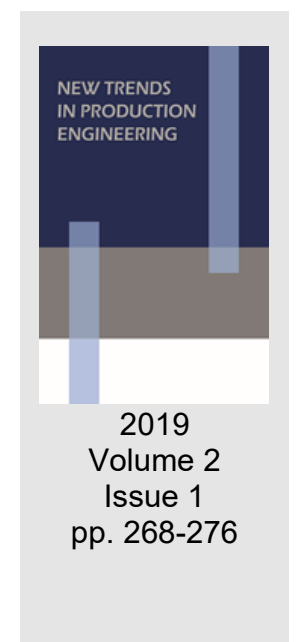

Date of submission to the Editor: 05/2019

Date of acceptance by the Editor: 07/2019

\section{INTRODUCTION}

Drill string consist of drill pipes and other elements connected together. Drill string consist of drill pipes and other elements connected each to other. The drilling quality depends on accuracy of the manufacturing of these pipe connectors. Connector consist of two parts -a box and a pin. Every has tapered thread surface of the equal size. The accuracy of these tapered thread surfaces are mostly determined by thread profile and pitch diameter accuracy. Setup precision of the cutting tool relative to workpiece axis very influences on thread accuracy. The radial bias of the tool is obvious factor because it influences on diameter size but tangential bias is not so much obvious. It needs special study. On our mind the radial bias of the lathe tool setup greatly affects the profile precision of the tool joint tapered thread of the smallest sizes.

\section{REVIEW OF RESEARCHES AND PUBLICATIONS}

According to standard API 7 (Fig. 1), the group of the smallest size drill string connectors includes four types of the tapered thread: NC10, NC12, NC13, NC16. Their major diameters are: $30,35,38,44(\mathrm{~mm})$ in accordance. There are signs on the figure 1:1 - box thread, 2 - pin thread, $d$ - major thread diameter. Obviously it must be variant becouse it is tapered thread.

Investigation of the thread accuracy made by lathe machining as a rule shows cutting velocity influence on pitch diameter deviation or shows variances of the pitch diameter under the different lubrication methods (Li Kang et al., 2014). There are methods that offer to increase wear resistance of the drill pipe tapered thread connection by electromechanical surface hardening (Fedorov et al., 2017). Due to those it is possible to increase the hardness of the thread surface made by lathe machining before. But it doesn't allow to increase the tensile strength. Only lathe machining of the high strength steel leads to receive drill pipes that have tensile strength more then $1270 \mathrm{MPa}$. That kind of pipes are 
needed especially for modern widely used process of horizontal drilling. But achieving of that tensile strength by lathe is possible by using carbide insert into cutter tool only if its rake angle is negative. In particular investigations based on using of the carbide insert that is provided by rake angle equal -7 (Baizeau et al., 2015) prove the possibility of that kind machining.

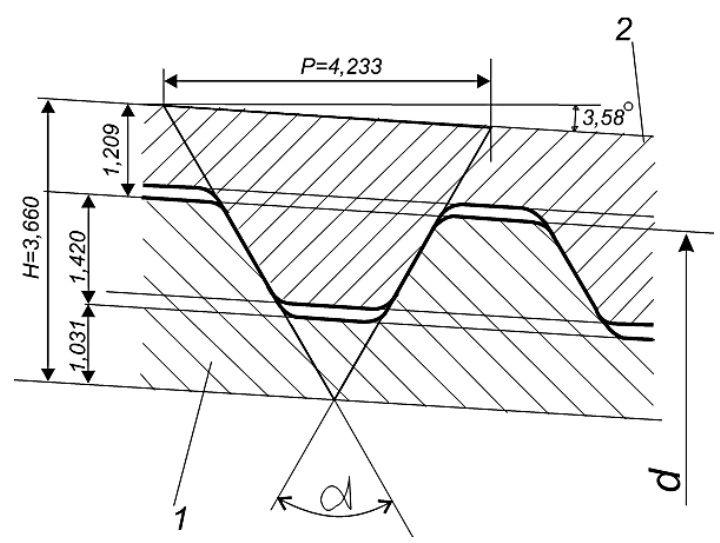

Fig. 1 Schema of the tool-joint tapered thread according to API 7 (thread profile VI) Marked with symbols: 1 - pin, 2 - box

The fundamental technological study of threading turning process include the recommendations about value of rake angle applying for different types of steel according to its tensile strength (Fomin, 2007).In particular for the machining of the thread made of steel with tensile strength before $1170 \mathrm{MPa}$ the recommended value of rake angle is $0^{\circ}$. If applied steel has tensile strength is after $1170 \mathrm{MPa}$ to $1765 \mathrm{MPa}$ than the recommended value of rake angle equal $-5^{\circ}$ (Fomin, 2007).

The investigations made for the purpose of receiving the design and technological solving's for increasing of thread precision during lathe (Laurențiu Slătineanu et al., 2017). In the article the application of lathe device for correction of cutter setup during machining is explained. In the article the application of lathe device for correction of cutter setup during machining is explained. But there are not data about influence of the tangential deviation on the accuracy of the thread profile.

In the article (Koleva et al., 2017) it is offered to provide checking of the thread profile by applying of the cutter tool insert. This technique is effective because the any additional time for checking is not spent. It gives the redusing of cost because the any special sensors aren't applied. But in the method there are disadvantage come from the tool setup because its deviations are not accounted in it.

\section{Previous analytical author researches about influence of inaccuracy tool setup relatively thread axis on its precision}

Analytical evaluations of the enfluance of tangential deviation of the tool setup relatively thread axis on thread precision are the main part of the article (Onysko and Psiuk, 2017). The lathe tool provided with carbide insert include nonzero rake angle $\gamma$ and nonzero inclination angle $\alpha$. 


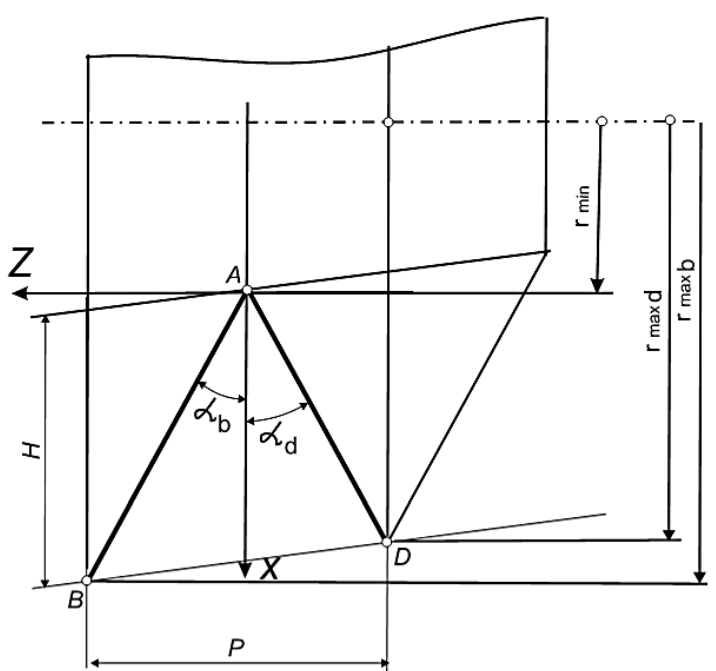

Fig. 2 Schema of the profile of the tool-joint tapered thread in coordinates ZOX.

Signs on the drawing are mean:

$r_{\min }$ - internal radius of thread; $r_{\operatorname{maxd}}$ - external radius of thread in point $D$, $r_{\text {maxb }}$ - external radius of thread in point $B$

Because any deviation of the rake face from thread axis lead to shape formed as convoluted sqrew then the profile of flanks $A D$ and $A B$ in coordinates $Z O X$ (look at Fig. 2) can be defined by using that transcendentical equation (Onysko and Psiuk, 2017):

$$
z(x)=\tan \left(\alpha_{i}\right) x \frac{\sin \tau}{\sin \eta}-\frac{P}{2 \pi} \tau
$$

where:

$$
\tau=\eta-\arcsin \left(\frac{r_{\min } \sin \eta}{x}\right) x
$$

Values $\eta$ by algorithm (Onysko and Psiuk, 2017) is defended by different formulas intended for flanks $A D$ and $A B$. So for flank $A D$ :

$$
\eta=\gamma+\gamma_{1}+\mu
$$

where:

$$
\mu=\left(\frac{q}{t}\right)
$$

where:

$$
\begin{gathered}
q=\tan \left(\frac{H \cdot \cos \varphi}{2 \sin \left(60^{\circ}+\varphi\right)}\right) \\
t=\frac{H \cdot \cos \varphi}{\sin \left(60^{\circ}+\varphi\right)} \sqrt{\left(\left(1-\sin ^{2} 30^{\circ} \cos ^{2} \lambda\right)-\frac{\tan ^{2}(\lambda)}{4}\right)}
\end{gathered}
$$

and for flank $A B$ :

$$
\eta=\arcsin \left(\frac{\sin 30^{\circ} \sin \left(\lambda_{d e v}+\lambda\right)}{\sqrt{1}-\sin ^{2} 30^{\circ} \cos ^{2}\left(\lambda_{d e v}+\lambda\right)}\right)-\gamma-\gamma_{1}
$$

where for both flanks $A B$ and $A D$ using Figure 5 value $\gamma_{1}$ is defined:

where:

$$
\gamma_{1}=\arcsin \left(\frac{h_{d e v}}{r_{\text {min }}}\right)
$$

$$
h_{d e v}=r_{\min } \sin \left(\gamma_{d e v}+\arcsin \frac{a}{r_{\min }}\right)
$$


where:

$r_{\min }$ - internal radius of thread (on Fig 2, 3 correspond to point A);

$h_{d e v}$ - value of deviation of the tool nose due to position rotated error. There two variants of cutters on schema - with positive and negative rake angle $\gamma$. In case positive angle the rake face position has deviation $h_{d e v}=h_{2}$, In negative case $h_{\text {dev }}=h_{1}$;

$\gamma$ - rake angle in nose at point $A$.;

$\gamma_{\text {dev }}$ - angle deviation in reference plane YOX. On Fig. 3 it corresponds to rotation of the rake face relatively to nose $A$ on the value $-\gamma$, or $+\gamma$;

$a-$ tangential deviation of the rake face relatively to thread axis;

$P$ - thread pitch. If profile form VIP $=4.233 \mathrm{~mm}$ (look at. Fig. 1);

$H$ - depth of fundamental triangle. If profile form $\mathrm{VIH}=3.660 \mathrm{~mm}$ (look at. Fig. $1)$;

$\phi$ - tapered angle. If profile form $\mathrm{VI} \varphi=3.58^{\circ}$ (look at. Fig. 1);

$\lambda$ - lead angle at pitch diameter;

$\lambda_{\text {dev }}$ - angle deviation in reference plane ZOY;

$\alpha_{i}$ - angle between flank of thread and normal to axis of screw. According to standard API 7 it equal $30^{\circ}$.

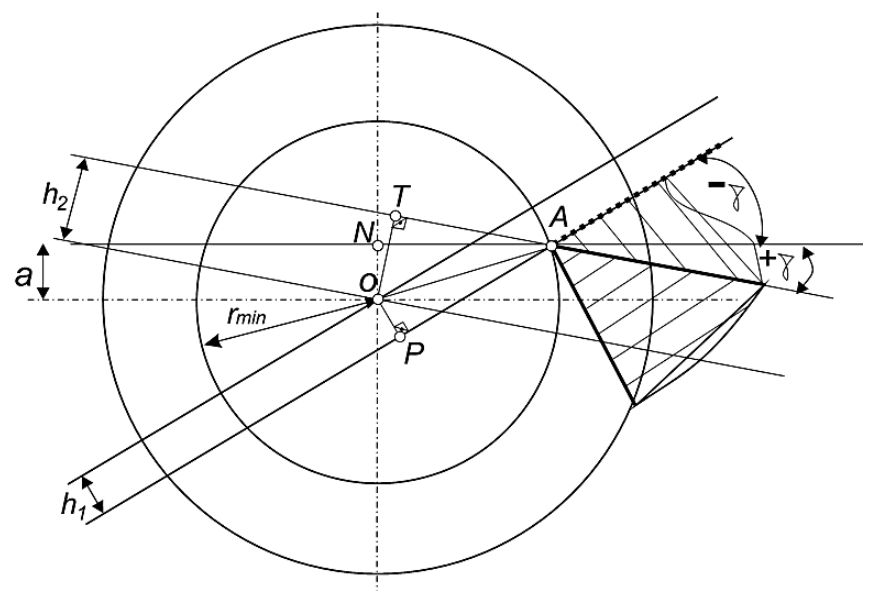

Fig. 3 Scheme for calculating of the accuracy of the profile angle relatively on the vertical deviation of the nose of the cutter. Symbols are indicated by:

A - nose point of the cutter; $\mathrm{O}$ - thread axis; $\mathrm{a}$ - tangential deviation of the nose relatively to axis

$\mathrm{O}, \mathrm{h}_{2}-$ correspond to value of NO, $h_{1}-$ correspond to value of NP

Using the scheme in Fig. 2 you can apply formulas to calculate the angles of the profile $\alpha_{\mathrm{b}} \mathrm{i} \alpha_{\mathrm{d}}$ of the tapered thread made by cutter with nonzero value of the rake angle $\gamma$ and inclinational angle $\lambda$ (Onysko and Psiuk, 2017):

where:

$$
\begin{aligned}
& \alpha_{b}=\arctan \frac{Z_{\left(r_{\max b}\right)}}{\left(r_{\max b}-r_{\text {min }}\right)} \\
& \alpha_{d}=\arctan \frac{Z_{\left(r_{\max d}\right)}}{\left(r_{\max d}-r_{\text {min }}\right)}
\end{aligned}
$$

$z\left(r_{\max b}\right)$ using formula 2 if $\mathrm{x}=r_{\max b}$,

and $z\left(r_{\max d}\right)-$ if $\mathbf{x}=r_{\max d}$. 
Within the framework of the research article (Onysko and Psiuk, 2017), it is limited to three standard sizes of drill connector thre with diameters from 65 to $203 \mathrm{~mm}$. The authors concluded that for such sizes, a tangential displacement of $0.1 \mathrm{~mm}$ in combination with the inaccuracy of the rake angle and the angle of inclination of the cutting edge of $0.1^{\circ}$ induces an increase in the thread profile angle on the whole by $0.01-0.02^{\circ}$. It is not more than $1.3 \%$ fraction of the tolerance.

Investigation of the influence of the error of the tool setup on the accuracy of the profile by the numerical and analytical method.

The definition of the profiles of a cutting tool for normal and synchronized rotations by numerical and analytical methods is analyzed (Zanger et al., 2017). Both models showed the same geometry of the cutting tool, except that the analytical model showed bifurcations that lead to a trimming in the processing of the part. But this article deals solely with the manufacture of cylindrical threads.

In the paper (Kopei et al., 2019), it is proposed to simulate tapered threads in the FreeCAD environment using programming in Pithon.

Modern CADs provide an opportunity to analyze the stress distribution between the surfaces of the box and the pin in conjunction (Wittenberghe et al., 2009) and (Wang et al., 2016). These studies confirm that the first and last turns of the subject are the most exposed.

\section{Research focus, objectives and hypothesis}

The authors offer on the basis of programming, to make an automated calculation of the accuracy of the NC10 tapered thread profile, Since the specified size is the smallest among drill connector, the probability of a significant impact of the tangential displacement of the lathe cutter is real. To verify the validity of the results, 3D modeling of the lathe machining of thread and the receipt of profile deviations is used.

\section{METHODOLOGY OF RESEARCH}

To construct a parametric geometric model and calculate the angle values, FreeCAD and the program anglesZamok.py using the FreeCAD API are used. The program code is available at the address https://github.com/vkopey/ Thread-turning-simulator. On the basis of analytical formulas 1-11, a software application for the automated calculation of NC10 tapered thread profile is made. In the calculation of the input parameters is the rake angle of cutter and the lead angle of thread, as well as the value of the tangential displacement of the nose of the cutter relative to the axis of the thread. The study focuses on examining the first and last turns of the thread because of their greatest load during the operation of the connector.

\section{RESULTS}

Using the application, a Table 1 has been generated. The Table data is obtained for tool-joint tapered thread NC10. The calculation is carried out for the values 
of the static rake angle (column 2) at the nose of the cutter $\lambda=0^{\circ}$ and $\lambda=-5^{\circ}$. Numbers of turning sills are in column 5. The angle of inclination of the cutting edge (column 3 ) is $0^{\circ}$ (rows $1-20$ ) and the corresponding lead angle $\lambda=3.57^{\circ}$ for number 1 (rows 21-23) and $\lambda=2.44^{\circ}$ for the last rope (rows 24-26). The value of the tangential deviation a (column 4 ) is selected as negative and positive for such values modulo: $0,0.05,0.1,0.2(\mathrm{~mm})$. The results of the automated application of the algorithm based on formulas 1-11 are shown in columns 6 and 8. The results of calculating the profile angles of the section on the basis of a parametric model, the fragment of which is illustrated in Fig. 4 is shown in columns 7 and 9 . They are executed solely for the tangential displacement $\mathrm{a}=$ $0.2 \mathrm{~mm}$ and $\mathrm{a}=-0.2 \mathrm{~mm}$. Tolerance of profile $40^{\prime}$. Nominal $30^{\circ}$.

Table 1 Value of half profile angle (left and right) depend on the tangential deviation of the cutter position

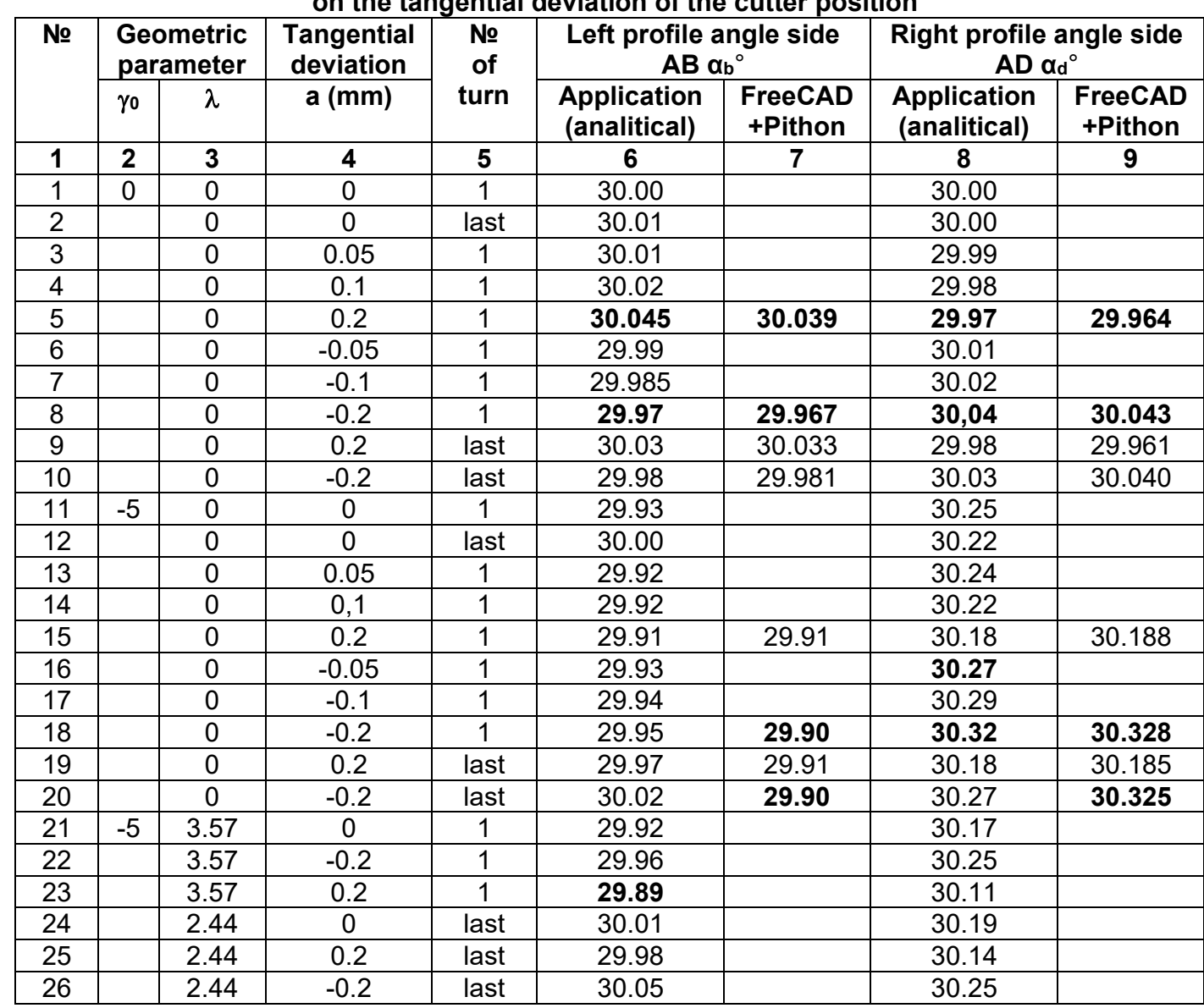

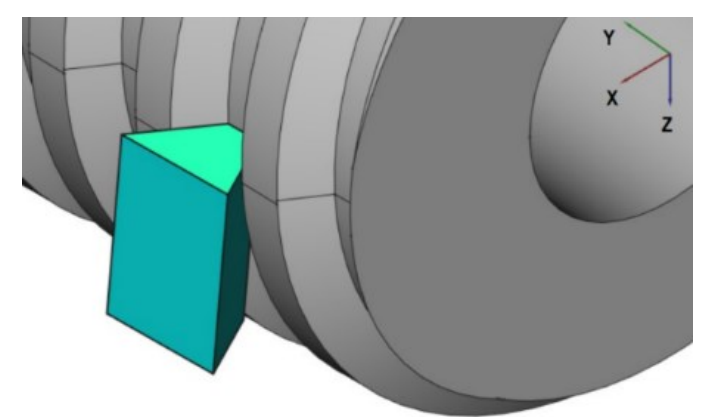

Fig. 4 Geometrical model of the thread lathe process of the NC10 pin in FreeCAD application 


\section{DISCUSSION}

1. Table 1 includes data of the algorithmic counting of the profile angles according formulas 1-11 of tangential deviation $a$ is from 0 to $0.2 \mathrm{~mm}$ and from o to $-0.2 \mathrm{~mm}$. No sudden changes (rows 6,8 ) aren't watched. This, in the opinion of the authors, gives rise to confidence in the proposed algorithm.

2. Results that correspond to biggest deviations are drawn bold. For example, in row 18 we have the largest absolute deviation of $0.32^{\circ}$ (column 8 ), the deviation $-0.11^{\circ}$ (row 23 , column 6 ) shows the largest deviation of the left sideprofile anglet.

3. Table 2 summarizes the results obtained by two methods:

- calculate application based on formulas 1-11 (columns 2.6).

- calculation based on geometric modelling in the FreeCAD environment (column 4.8).

4. The reliability of the results is shown in columns 5 and 9 where the relative error value is shown when comparing the two methods. There are rather controversial row 20 and partly of row 5 in the opinion of the authors. There is a significant relative error of $33 \%$ (row 10, column 9 ), but in absolute terms, the fraction of the deflection by the size of the profile angle (40') is only $4.5 \%$, and even for the method of FreeCAD+Pithon it is less than $7 \%$.

Table 2 Values of relative errors and fractions of the tolerance of the profile angle

\begin{tabular}{|c|c|c|c|c|c|c|c|c|}
\hline \multirow{2}{*}{$№$} & \multicolumn{3}{|c|}{ Left profile angle, side AB } & \multicolumn{4}{c|}{ Right profile angle, side AD } \\
\cline { 2 - 9 } & applicat & $\begin{array}{c}\text { \% of } \\
\text { tolerance }\end{array}$ & $\begin{array}{c}\text { FreeCAD } \\
\text { +Pithon }\end{array}$ & $\begin{array}{c}\text { relative } \\
\text { \% }\end{array}$ & applicat & $\begin{array}{c}\text { \% of } \\
\text { tolerance }\end{array}$ & $\begin{array}{c}\text { FreeCAD } \\
\text { +Pithon }\end{array}$ & $\begin{array}{c}\text { relative } \\
\%\end{array}$ \\
\hline $\mathbf{1}$ & $\mathbf{2}$ & $\mathbf{3}$ & $\mathbf{4}$ & $\mathbf{5}$ & $\mathbf{6}$ & $\mathbf{7}$ & $\mathbf{8}$ & $\mathbf{9}$ \\
\hline 5 & $\mathbf{3 0 . 0 4 5}$ & 6.8 & $\mathbf{3 0 . 0 3 9}$ & 13 & $\mathbf{2 9 . 9 7}$ & 4.5 & $\mathbf{2 9 . 9 6 4}$ & 0.6 \\
\hline 8 & $\mathbf{2 9 . 9 7}$ & 4.5 & $\mathbf{2 9 . 9 6 7}$ & 4 & $\mathbf{3 0 . 0 4}$ & 6.0 & $\mathbf{3 0 . 0 4 3}$ & 7.5 \\
\hline 9 & 30.03 & 4.5 & 30.033 & 1 & 29.98 & 3.0 & 29.961 & 2.1 \\
\hline 10 & 29.98 & 3.0 & 29.981 & 1 & 30.03 & 4.5 & 30.040 & 33 \\
\hline 15 & 29.91 & 13.6 & 29.97 & 6.5 & 30.18 & 27.2 & 30.188 & 4 \\
\hline 18 & 29.95 & 7.5 & $\mathbf{2 9 . 9 0}$ & 5 & $\mathbf{3 0 . 3 2}$ & 48.5 & $\mathbf{3 0 . 3 2 8}$ & 2.5 \\
\hline 19 & 29.97 & 4.5 & 29.91 & 6 & 30.18 & 27.2 & 30.185 & 2.7 \\
\hline 20 & 30.02 & 3.0 & $\mathbf{2 9 . 9 0}$ & 40 & 30.27 & 40.9 & $\mathbf{3 0 . 3 2 5}$ & 20 \\
\hline
\end{tabular}

Using the data of the Table 1,2 come to the conclusion that maximum fraction of the tolerance of profile angle are (rows 3 and 6 ):

$-6.0 \%$ if $\mathrm{a}=-0,2 \mathrm{~mm}$ and $\gamma=0$ (row 8);

$-48.5 \%$ if $\mathrm{a}=-0,2 \mathrm{~mm}$ and $\gamma=-5$ (row 23);

$-40.5 \%$ if $\mathrm{a}=-0,05 \mathrm{~mm}$ and $\gamma=-5$ (row 16$)$.

\section{CONCLUSION}

1. Tangential deviation of the tool nose setup during of the lathe machining of the tool-joint tapered thread of the smallest size NC10 influence thread profile accuracy not so mach. Fraction of the tolerance of profile angle can not be more than $5 \%$ if tangential deviation $a=-0.2 \mathrm{~mm}$ and rake angle $\gamma=0^{\circ}$.

2. This fraction of the tolerance of profile angle can be more than $40 \%$ if tangential al deviation $a=-0.05 \mathrm{~mm}$, rake angle $\gamma=-5^{\circ}$. It cause doubt due to 
applying of the tool without its cutting edge profile correction for thread manufacturing.

\section{REFERENCES}

Baizeau, T., Campocasso, S., Fromentin, G., Rossi, F., and Poulachon G. (2015). Effect of rake angle on strain field during orthogonal cutting of hardened steel with c-BN tools. In: $15^{\text {th }}$ CIRP Conference on Modelling of Machining Operations. pp. 166171. DOI: $10.1051 /$ matecconf $/ 201711201005$

Fedorova L., Fedorov S., Ivanova Y. and Voronina M. (2017), Increase of Wear Resistance of the Drill Pipe Thread Connection by Electromechanical surface Hardening. International Jornal of Applied Engineering and Research, Volume 12, Namber 18, pp. 7485-7489.

Fomin, E. (2007). Povyshenye stojkosty itochnostirezbov yx rezczovna osnove modelirovanyya proces sarezbona rezaniya. PhD, Moscow State Technological University "Stankin".

Koleva S., Enchev M., Szecsi T.(2017). Compensation of the deviations caused by mechanical deformations during machining of threads. In: Manufacturing Engineering Society International Conference. [online] Vigo (Pontevedra): NCTT, pp. 480-486. Available at: https://www.sciencedirect.com/ [Accessed 24 June. 2019].

Kopei V., Onysko O., Panchuk V. (2019) The Application of the Uncorrected Tool with a Negative Rake Angle for Tapered Thread Turning. In: Ivanov V. et al. (eds) Advances in Design, Simulation and Manufacturing II. DSMIE 2019. Lecture Notes in Mechanical Engineering. Springer, Cham. pp. 149-158. https://doi.org/10.1007/978-3-030-22365-6_15

Laurențiu Slătineanu, Miroslav Radovanovic, Margareta Coteață, Irina Beșliu, Oana Dodun, Ionel Coman, and Sergiu-Constantin Olaru.(2017).Requirements in designing a device for experimental investigation of threading accuracy. In: MATEC Web of Conferences 112, 01005. pp. 1-6 DOI: 10.1051/matecconf/201711201005

Li Kang, Jiang Li and Chen Ming (2014). Experimental study on the influence of cutting parameters on thread precision of external thread turning. Material Science Forum. Vol. 770., Trans Tech Publications, Switzerland, pp. 7-12. doi: 10.4028/www.scientific. net/MSF.770.7

Onysko, O. R., Psiuk, M. I. (2017). Analiz zabezpechennia tochnosti profiliu zamkovoi narizi vyhotovlenoi riztsiamy iz zahalnym polozhenniam perednoi poverkhni ta zadanoi tochnistiu yii vstanovlennia. Visnyk NTU «KhPI». Seriia: Tekhnolohii u mashynobuduvanni. pp. 10-17.

Van Wittenberghe J., De Baets P., De Waele W. and Van Autrève S. (2009) Numerical and experimental study of the fatigue of the threaded pipe couplings. Wit Transactions on Engineering Sciences, Vol 62 pp. 163-164, http://www.witpress.com, /doi:10.2495/SECM090151 [Accessed 23 June 2019].

Wang Yu., Xia Bairu, Wang Zhiqiao and Chai Chong.(2016) Model of a new joint thread for a drilling tool and its stress analysis used in a slim borehole. Mech. Sci., 7, 189-200, 2016 http://www.mech-sci.net/7/189/2016/doi:10.5194/ms-7-189-2016l [Accessed 21 June 2019].

Zanger F., Sellmeier V., Klose, J., Bartkowiak, M., Schulce, V. (2017). Comparison of modeling methods to determine cutting tool profile for conventional and synchronized whirling. In: $16^{\text {th }}$ CIRP Conference of Modelling of Machining Operations. pp. 222-227. doi: 10.1016/j.procir.2017.03.216 


\begin{abstract}
.
The drill string consists of connected drill pipes and other elements. The connection is carried out by screwing of the drill string elements with the help of tool-joint tapered thread. The operational characteristics of the drill pipes depend of the manufacture precision of these tooljoints mostly. The accuracy of the thread is regulated by the accuracy of its profile and the accuracy of its pitch diameter value. The accuracy of the tapered thread manufacturing on the lathe in its depending on the values of the geometric parameters of the lathe tool and the values of deviations of its installation relatively to the workpiece axis is investigated. It is proved that for the tapered thread of form VI profile used for connection of drill pipes with the diameter from $30 \mathrm{~mm}$ to $44 \mathrm{~mm}$ the most influential factor, in relation to the accuracy of the thread profile is the value of the rake angle. Application of the rake angle value up to $-5^{\circ}$ according to the research data leads to a deviation from the specified profile of $0.3^{\circ}$, which is more than $35 \%$ of the declared standard tolerance on deviations from the profile. Also, the influence of the back rake angle value on the value of the deviation from the standard pitch diameter of the thread is proved. It is proved that the magnitude of the tangential displacement of the nose of the cutter relatively to the axis of the thread up to $-0.2 \mathrm{~mm}$ can cause a deviation of the profile angle of $0.18^{\circ}$, which is $27 \%$ of the standard tolerance.
\end{abstract}

Keywords: drill string, back rake angle, tool-joint tapered thread, pitch diameter, lathe tool 